\title{
RESPOSTA DO MILHO A FONTES E MODOS DE APLICAÇÃO DE FÓSFORO DURANTE TRÊS CULTIVOS SUCESSIVOS EM SOLO DA REGIÃO DO CERRADO ${ }^{1}$
}

\author{
Maize response to phosphorus sources and application methods during three \\ successive cultivations in soil of the Cerrado region
}

\author{
Álvaro Vilela de Resende ${ }^{2}$, Antonio Eduardo Furtini Neto ${ }^{3}$, Vera Maria Carvalho Alves, \\ Joel Augusto Muniz ${ }^{5}$, Nilton Curi ${ }^{6}$, Fabiano José do Lago ${ }^{7}$
}

\begin{abstract}
RESUMO
Objetivou-se comparar fertilizantes fosfatados em diferentes modos de aplicação, durante três cultivos sucessivos de milho, num Argissolo Vermelho já adubado anteriormente. Foi utilizado um fatorial 4 x 2+1, envolvendo quatro fontes de P (superfosfato triplo-ST, termofosfato magnesiano - TM, fosfato reativo de Arad - FR e fosfato natural de Araxá - FA), duas formas de aplicação (a lanço ou no sulco de plantio), e uma testemunha (sem P) como tratamento adicional. Foram fornecidos $180 \mathrm{~kg} \mathrm{ha}^{-1}$ de $\mathrm{P}_{2} \mathrm{O}_{5}$ no primeiro cultivo, com base nos teores totais das fontes. Para os cultivos seguintes, não foi feito preparo do solo. Determinaram-se os teores de nutrientes no solo e nas folhas de milho e a produção de grãos. As respostas aos tratamentos foram mais discrepantes inicialmente e tenderam à eqüidade com os cultivos sucessivos. Nas duas primeiras safras, as fontes de maior solubilidade (ST e TM) ocasionaram as maiores produções. Os fosfatos naturais (FR e FA) apresentaram aumento de eficiência com o tempo. A aplicação localizada do FR proporcionou alta produtividade na terceira safra. $\mathrm{O}$ residual de antigas adubações e as condições climáticas influenciaram os efeitos dos tratamentos.
\end{abstract}

Termos para indexação: Fertilidade do solo, fosfato reativo, fosfato natural, adubação fosfatada, Zea mays.

\begin{abstract}
The objective of this study was to compare phosphate fertilizers in different methods of application during three successive maize cultivations in a Red Argisol (Hapludults) which had been previously fertilized. Treatments arranged in a $4 \times 2+1$ factorial design combined four $\mathrm{P}$ sources in the amount of $180 \mathrm{~kg} \mathrm{ha}^{-1} \mathrm{P}_{2} \mathrm{O}_{5}$ (triple superphosphate - TS, magnesium termophosphate - MT, Arad reactive rock phosphate - RP, and Araxá rock phosphate - AP), two application methods (broadcasted or banded in the seeding furrow), and a check plot (without $\mathrm{P}$ ) as an additional treatment. The applied $\mathrm{P}$ ratio was based on the total $\mathrm{P}_{2} \mathrm{O}_{5}$ content of each fertilizer. After the first cultivation, the soil was no longer revolved. Soil and leaf nutrient concentrations, and the grain yield were determined. The responses to treatments were more contrasting initially and tended to level off with successive cultivations. In the first two cultivations, the most soluble sources (TS and MT) promoted greater yields. The rock phosphates (RP and AP) presented increased efficiency with time. Banded application of RP provided a higher grain yield in the third cultivation. The residual effect of previous fertilizations and the climatic conditions influenced the effects of the treatments.
\end{abstract}

Index terms: Soil fertility, reactive rock phosphate, rock phosphate, phosphated fertilization, Zea mays.

Recebido para publicação em 17 de junho de 2004 e aprovado em 6 de dezembro de 2005)

\section{INTRODUÇÃO}

$\mathrm{Na}$ avaliação das respostas ao fósforo, além das diferenças entre solos e culturas, é preciso considerar a interferência de outros fatores, como as características e a forma de aplicação dos fosfatos, o histórico da área, o tempo decorrido após a adubação, as diferenças varietais, o clima, o método de preparo do solo e o sistema de produção (ANGHINONI, 2003; NOVAIS \&
SMYTH, 1999; PROCHNOW et al., 2003; SOUSA \& LOBATO, 2003). Experimentos de longa duração são fundamentais para respaldar inferências acerca da eficiência de manejo da adubação fosfatada, uma vez que permitem contornar problemas relativos às inconstâncias das respostas observadas em anos isolados e avaliar um forte condicionante da eficiência, que é o efeito residual dos tratamentos (RAJAN et al., 1996; SOUSA \& LOBATO, 2003).

${ }^{1}$ Parte da Tese de Doutorado do primeiro autor, Departamento de Ciência do Solo/DCS - Universidade Federal de Lavras/UFLA - Trabalho apoiado pelo CNPq, Serrana Fertilizantes S.A., Fertilizantes Ouro Verde S.A. e Fertilizantes Mitsui S.A.

${ }^{2}$ Engenheiro Agrônomo, D.Sc., Pesquisador, Embrapa Cerrados - Cx. P. 08223 - 73310-970 - Planaltina, DF - alvaro@cpac.embrapa.br

${ }^{3}$ Engenheiro Agrônomo, D.Sc., Professor Adjunto - Departamento de Ciência do Solo/DCS - Universidade Federal de Lavras/UFLA - Cx. P. 3037 37.200-000 - Lavras, MG - Bolsista do CNPq - afurtini@ufla.br

${ }^{4}$ Engenheira Agrônoma, D.Sc., Pesquisadora, Embrapa Milho e Sorgo - Cx. P.151 - 35701-970 - Sete Lagoas, MG - vera@cnpms.embrapa.br

${ }^{5}$ Engenheiro Agrônomo, D.Sc., Professor Titular - Departamento de Ciências Exatas/DEX - Universidade Federal de Lavras/UFLA - Cx. P. 3037 37.200-000 - Lavras, MG -Bolsista do CNPq - joamuniz@ufla.br

${ }^{6}$ Engenheiro Agrônomo, Ph.D. - Professor Titular - Departamento de Ciência do Solo/DCS - Universidade Federal de Lavras/UFLA - Cx. P. 3037 37.200-000 - Lavras, MG - Bolsista do CNPq - niltcuri@ufla.br

${ }^{7}$ Acadêmico do curso de Agronomia - Universidade Federal de Lavras/UFLA - Cx. P. 3037 - 37.200-000 - Lavras, MG - Bolsista de Iniciação Científica do CNPq. 
Existe consenso de que os fosfatos mais solúveis proporcionam maior resposta no ano da aplicação, enquanto os fosfatos naturais têm menor eficiência inicial. Com o tempo, as diferenças de eficiência entre fontes tendem a diminuir (HOROWITZ \& MEURER, 2003; SOUSA \& LOBATO, 2003). Por outro lado, a indisponibilização do fósforo liberado ocorre de forma mais intensa no caso das fontes de alta solubilidade em comparação aos fosfatos naturais que, ao liberarem o nutriente de forma mais lenta, minimizam o processo de fixação (NOVAIS \& SMYTH, 1999). A escolha da fonte e do modo de aplicação ainda representam alguns dos principais questionamentos quando se trata de estratégias de fornecimento de P. A influência do modo de aplicação na resposta da planta, levando em conta as diferenças de solubilidade dos fosfatos, ainda é motivo de controvérsias entre pesquisadores, principalmente em relação aos fosfatos naturais nacionais e importados (LOPES, 1999; NOVAIS, 1999).

Em áreas já adubadas anteriormente, os efeitos da aplicação de fosfatos podem não seguir os padrões das respostas normalmente verificadas em solos virgens. Solos com certa reserva do nutriente tendem a favorecer a equiparação das respostas a distintas estratégias de manejo da adubação fosfatada (ANGHINONI, 2003; KAMINSKI \& PERUZZO, 1997).

As crescentes produtividades de milho alcançadas no País somente são conseguidas com suprimento de $\mathrm{P}$ em quantidades compatíveis com a demanda da cultura e, normalmente, aplicações mais pesadas de fosfatos são requeridas (COELHO \& ALVES, 2003). Há ainda muita dificuldade em estabelecer recomendações de adubação otimizadas, baseadas em critérios para alta eficiência de manejo. No presente trabalho, objetivou-se avaliar as respostas do milho à adubação fosfatada com diferentes fontes e modos de aplicação, em solo já cultivado da região do Cerrado, considerando os resultados isolados de três cultivos sucessivos.

\section{MATERIALE MÉTODOS}

O estudo foi realizado na Fazenda Boa Vista, município de Itumirim, MG. O solo da área experimental é um Argissolo Vermelho Distrófico típico (antigo Podzólico Vermelho-Escuro), textura argilosa. O local foi anteriormente cultivado e adubado e há cerca de dez anos não era utilizado para lavouras, permanecendo coberto por vegetação espontânea dominada por capim-braquiarão (Brachiaria brizantha). A planta-teste foi o milho, sendo utilizados híbridos triplos da Embrapa Milho e Sorgo. Foram conduzidos três cultivos consecutivos em condições de sequeiro, nos anos agrícolas 2000/2001, 2001/2002 e 2002/ 2003. Os híbridos de milho foram HT 9710-11, HT 7105-3 e BRS 3003, respectivamente, para o primeiro, segundo e terceiro cultivos.

As parcelas corresponderam a cinco linhas de milho de $6 \mathrm{~m}$ de comprimento e $0,9 \mathrm{~m}$ espaçadas entre si (área útil central com três linhas de $4 \mathrm{~m}$ de comprimento). $\mathrm{O}$ experimento foi instalado em delineamento de blocos casualizados, com quatro repetições. Os tratamentos consistiram de um fatorial $4 \times 2+1$, combinando quatro fontes de fósforo na dose de $180 \mathrm{~kg} \mathrm{ha}^{-1}$ de $\mathrm{P}_{2} \mathrm{O}_{5}$ (ST - superfosfato triplo, TM - termofosfato magnesiano Yoorin, FR - fosfato reativo de Arad, e FA - fosfato natural de Araxá), dois modos de aplicação (a lanço em área total e localizada no sulco) e uma testemunha sem fornecimento de fósforo (tratamento adicional).

Dada a baixa disponibilidade inicial do nutriente no solo (8 $\mathrm{mg} \mathrm{dm}^{-3}$, extrator resina de troca iônica), a dose de $\mathrm{P}$ foi definida considerando-se a necessidade de uma adubação corretiva. Tal dose também seria suficiente para proporcionar efeito residual para os três cultivos de milho. A aplicação de cada fonte foi baseada no teor de $\mathrm{P}_{2} \mathrm{O}_{5}$ total dos fertilizantes (Tabela 1). No modo de aplicação a lanço, os fertilizantes foram distribuídos manualmente em toda a área da parcela experimental e incorporados, com enxada, a $10 \mathrm{~cm}$ de profundidade. $\mathrm{Na}$ aplicação localizada, os fertilizantes foram distribuídos no sulco de plantio. A adubação fosfatada foi realizada apenas no primeiro cultivo, sendo as colheitas das duas safras subseqüentes resultantes da resposta do milho ao efeito residual dos tratamentos.

No primeiro ano, a área recebeu calcário dolomítico $\left(1,5 \mathrm{t} \mathrm{ha}^{-1}, \mathrm{PRNT}=100 \%\right)$, visando elevar o $\mathrm{pH}$ em água para valores próximos de 5,5. O preparo do solo com aração e gradagens foi realizado apenas na primeira safra. Após cada colheita, os restos culturais (parte aérea do milho) foram removidos das parcelas, deixando-se o solo em pousio. Para o segundo e terceiro cultivos, os sulcos de semeadura foram abertos com enxada, seguindo sua localização original. $\mathrm{O}$ fornecimento dos demais nutrientes foi baseado em análises do solo e recomendações de adubação para expectativas de produtividade acima de $8 \mathrm{t} \mathrm{ha}^{-1}$ de grãos (ALVES et al., 1999). As adubações de plantio foram feitas no sulco de semeadura e as de coberturas ao lado da linha de plantas, a partir do estádio de 6 a 8 folhas. Foram distribuídas cerca de dez sementes de milho por metro de sulco, deixando-se, após desbaste, cinco plantas por metro. Procedimentos específicos para o controle de plantas daninhas e de insetos praga foram adotados quando necessário, com o uso de herbicidas e inseticidas apropriados. 
TABELA 1 - Caracterização química e física dos fertilizantes fosfatados.

\begin{tabular}{|c|c|c|c|c|c|c|c|}
\hline \multirow[t]{2}{*}{ Fertilizantes ${ }^{1}$} & \multicolumn{7}{|c|}{ Características } \\
\hline & $\begin{array}{l}\mathrm{P}_{2} \mathrm{O}_{5} \\
\text { total }\end{array}$ & $\begin{array}{c}\mathbf{P}_{2} \mathbf{O}_{5} \\
\text { solúvel }\end{array}$ & $\mathrm{CaO}$ & MgO & $\mathrm{SiO}_{2}$ & $\begin{array}{c}\text { Equivalente } \\
\mathrm{CaCO}_{3}{ }^{2}\end{array}$ & Granulometria \\
\hline & ------- & - & $---\%-$ & -------- & ------ & & \\
\hline ST & 46,1 & $38,3^{3}$ & 13,0 & - & - & - & Granulado \\
\hline $\mathrm{TM}$ & 18,1 & $17,6^{4}$ & 20,0 & 7,0 & 25,0 & 50 & Pó \\
\hline FR & 33,1 & $9,4^{4}$ & 37,0 & - & - & - & Farelado \\
\hline FA & 22,7 & $4,3^{4}$ & 40,0 & - & - & - & Pó \\
\hline
\end{tabular}

Na Figura 1 são apresentados os dados pluviométricos referentes aos principais períodos de condução do experimento. Visualiza-se a inconstância do regime pluviométrico no primeiro cultivo, com períodos de suprimento subótimo de água, mormente no mês de janeiro, precedendo o florescimento do milho. De modo geral, as condições climáticas durante o segundo e terceiro cultivos foram bem mais favoráveis à cultura, com maior quantidade de chuva e distribuição mais regular em relação ao cultivo inicial.

Nos períodos de florescimento do milho, foram coletadas folhas para a determinação dos teores de nutrientes (MALAVOLTA et al., 1997). Ao final de cada cultivo, quantificou-se a produção de grãos em cada tratamento. Periodicamente, amostras de solo foram coletadas, nas parcelas visando ao acompanhamento dos efeitos dos tratamentos na profundidade de $0-20 \mathrm{~cm}$. No primeiro e segundo cultivos, as amostragens foram realizadas, respectivamente, aos 25 e aos 30 dias após a semeadura, com pontos de coleta nas linhas de plantio do milho. Após a colheita do terceiro cultivo, foi feita uma amostragem com pontos de coleta nas linhas e entrelinhas do milho, num total de dez pontos para compor a amostra referente a cada parcela, para caracterização final dos tratamentos (possíveis efeitos residuais). Dados de $\mathrm{pH}$, $\mathrm{Ca}$ e $\mathrm{Mg}$ foram obtidos de acordo com metodologias descritas em Embrapa (1999). O P disponível foi determinado utilizando-se a resina de troca iônica (RAIJ \& QUAGGIO, 1983).

Quando pertinente, os dados experimentais foram submetidos a análises de variância e testes de médias. As médias dos tratamentos componentes do fatorial foram comparadas entre si pelo teste de Tukey $(P \leq 0,05)$. Por meio do teste $\mathrm{F}(P \leq 0,05)$, obteve-se a significância do contraste comparando a média dos tratamentos do fatorial com a testemunha.

\section{RESULTADOS E DISCUSSÃO}

\section{Teores de nutrientes no solo e nas folhas de milho}

Conforme esperado, no primeiro ano, os teores de fósforo disponíveis no solo, determinados com resina de troca iônica, foram mais elevados nos tratamentos com aplicação localizada do nutriente, principalmente das fontes ST e TM, de maior solubilidade (Tabela 2). O teor original de $\mathrm{P}$ do solo não foi alterado nos tratamentos testemunha e FA aplicado a lanço, sendo a disponibilidade interpretada como baixa, de acordo com Raij et al. (1996) e Sousa \& Lobato (2003). Com o tempo, houve uma tendência de nivelamento dos valores de $\mathrm{P}$ disponível entre os tratamentos. Isso pode ser atribuído à ação conjunta de fatores como a extração pelo milho, interação com o solo (fixação) e dinâmica de liberação do $\mathrm{P}$ das fontes, fatores estes com graus de interferência variáveis em função dos tratamentos e do tempo decorrido da aplicação dos fosfatos.

De maneira geral, a fertilidade do solo em relação aos nutrientes $\mathrm{Ca}$ e $\mathrm{Mg}$ variou de média a alta, segundo as classes de interpretação de análise de solo indicadas para Minas Gerais (ALVAREZ et al., 1999). Deve-se destacar que as amostragens nos dois primeiros cultivos foram realizadas na linha de plantio, enquanto que no último cultivo foi feita uma amostragem mista, com pontos de coleta nas linhas e entrelinhas do milho após a colheita.

Ciênc. agrotec., Lavras, v. 30, n. 3, p. 458-466, maio/jun., 2006 

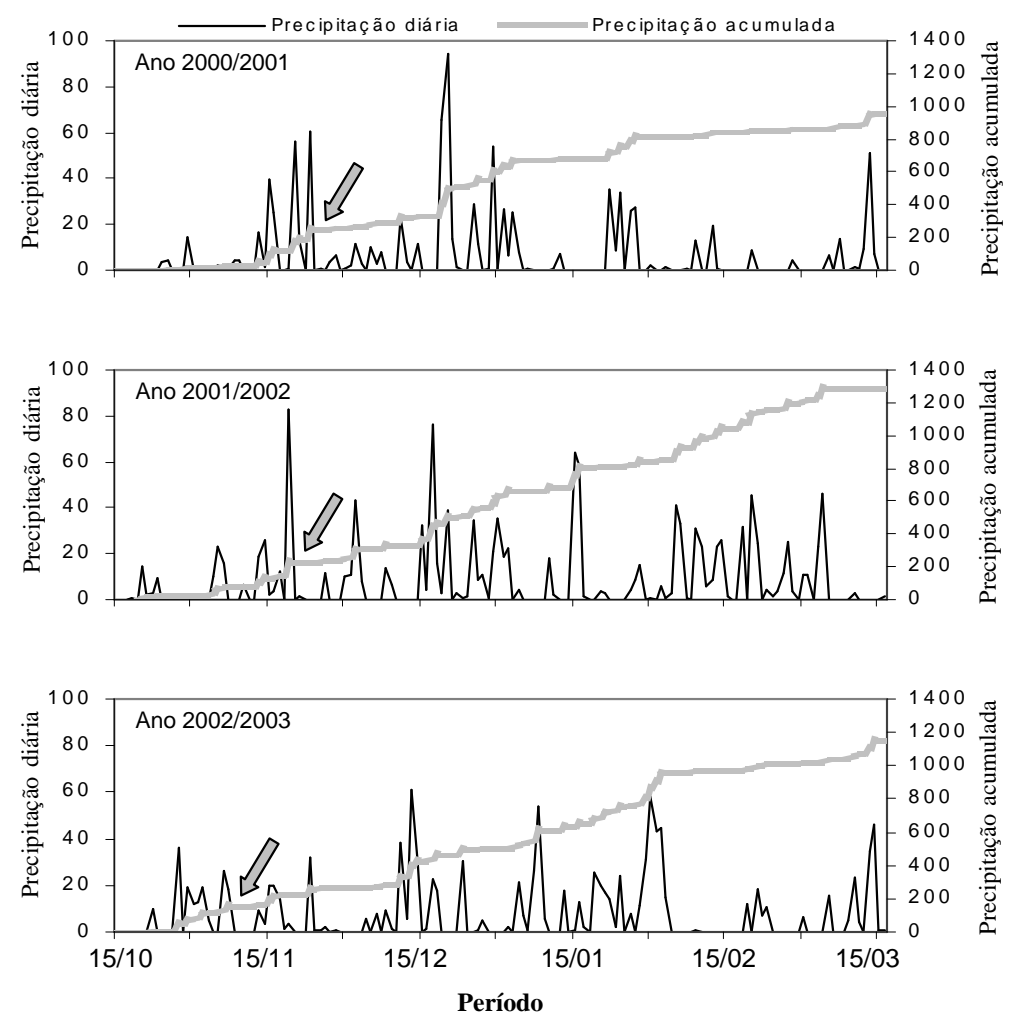

FIGURA 1 - Dados pluviométricos referentes aos períodos de condução dos três cultivos de milho (as setas indicam a época da semeadura).

TABELA 2 - Dados de pH, P $\left(\mathrm{mg} \mathrm{dm}^{-3}\right)$, e Ca e $\mathrm{Mg}\left(\mathrm{cmol}_{\mathrm{c}} \mathrm{dm}^{-3}\right)$ no solo ao longo do período de condução do experimento.

\begin{tabular}{|c|c|c|c|c|c|c|c|c|c|c|c|c|}
\hline \multirow[t]{2}{*}{ Tratamentos } & \multicolumn{4}{|c|}{$1^{0}$ cultivo ${ }^{1}$} & \multicolumn{4}{|c|}{$2^{0}$ cultivo ${ }^{2}$} & \multicolumn{4}{|c|}{$3^{0}$ cultivo ${ }^{3}$} \\
\hline & $\begin{array}{c}\mathrm{pH} \\
\text { água }\end{array}$ & $\begin{array}{c}\mathbf{P} \\
\text { Resina }\end{array}$ & $\mathbf{C a}$ & $\mathbf{M g}$ & $\begin{array}{c}\mathrm{pH} \\
\text { água }\end{array}$ & $\begin{array}{c}\mathbf{P} \\
\text { Resina }\end{array}$ & $\mathbf{C a}$ & Mg & $\begin{array}{c}\mathbf{p H} \\
\text { água }\end{array}$ & $\begin{array}{c}\mathbf{P} \\
\text { Resina }\end{array}$ & $\mathbf{C a}$ & $\mathbf{M g}$ \\
\hline Testemunha & 4,8 & 8 & 1,3 & 0,6 & 4,7 & 7 & 0,7 & 0,3 & 5,2 & 9 & 1,7 & 0,9 \\
\hline ST lanço & 5,0 & 10 & 1,6 & 0,5 & 4,8 & 9 & 0,9 & 0,4 & 5,0 & 10 & 1,6 & 1,2 \\
\hline TM lanço & 5,2 & 11 & 1,8 & 0,6 & 5,0 & 8 & 1,1 & 0,4 & 5,1 & 10 & 1,6 & 1,1 \\
\hline FR lanço & 5,0 & 10 & 1,2 & 0,4 & 4,9 & 8 & 0,8 & 0,3 & 5,1 & 12 & 1,8 & 0,5 \\
\hline FA lanço & 4,9 & 8 & 1,4 & 0,7 & 4,9 & 9 & 1,0 & 0,5 & 5,2 & 10 & 1,9 & 0,9 \\
\hline ST sulco & 5,1 & 30 & 1,9 & 0,6 & 5,1 & 28 & 1,3 & 0,4 & 5,1 & 10 & 1,8 & 0,7 \\
\hline TM sulco & 5,1 & 38 & 1,8 & 1,1 & 5,0 & 10 & 1,3 & 0,5 & 5,3 & 11 & 2,0 & 1,1 \\
\hline FR sulco & 5,0 & 19 & 1,4 & 0,6 & 5,0 & 13 & 1,2 & 0,4 & 5,2 & 13 & 2,0 & 0,7 \\
\hline FA sulco & 4,8 & 18 & 1,4 & 0,3 & 4,8 & 11 & 0,8 & 0,3 & 5,0 & 11 & 1,7 & 0,8 \\
\hline
\end{tabular}

(1) Amostragem aos 25 dias após a semeadura, com pontos de coleta nas linhas de plantio do milho $(0-20 \mathrm{~cm})$.

(2) Amostragem aos 30 dias após a semeadura, com pontos de coleta nas linhas de plantio do milho $(0-20 \mathrm{~cm})$.

${ }^{(3)}$ Amostragem após a colheita, com pontos de coleta nas linhas e entrelinhas do milho $(0-20 \mathrm{~cm})$. 
Esses procedimentos justificam os valores relativamente mais altos de $\mathrm{pH}, \mathrm{Ca}$ e $\mathrm{Mg}$ observados na análise ao final das três safras de milho (Tabela 2), uma vez que a adubação de plantio no sulco de semeadura normalmente promove considerável acidificação do meio próximo ao local de aplicação.

A adequação dos procedimentos referentes ao manejo da fertilidade do solo durante a condução do experimento foi confirmada nos resultados satisfatórios obtidos nas análises foliares do milho - dados disponíveis em Resende (2004). À exceção do fósforo, em geral, os teores de macro e micronutrientes situaram-se dentro ou muito próximos das faixas de valores correspondentes ao padrão nutricional de plantas de milho normais (MARTINEZ et al., 1999; OLIVEIRA, 2002). Em vários tratamentos, os teores foliares de $\mathrm{P}$ ficaram abaixo do limite de 2,5 $\mathrm{g} \mathrm{kg}^{-1}$, tido como adequado para o milho em Minas Gerais (MARTINEZ et al., 1999). Entretanto, quase sempre, esses teores superaram o limite mínimo de $1,8 \mathrm{~g} \mathrm{~kg}^{-1}$, considerado adequado para a cultura em solos de cerrado (OLIVEIRA, 2002). Os menores valores de $\mathrm{P}$ foliar foram obtidos no tratamento-testemunha $\left(1,6 \mathrm{~g} \mathrm{~kg}^{-1}\right.$ nos três cultivos).

\section{Produção de grãos}

Com relação à produção de grãos, nos dois primeiros cultivos somente houve efeito significativo das fontes de fósforo (Tabela 3), enquanto que no terceiro ocorreu interação de fontes $x$ modos de aplicação (Tabela 4).

As produções obtidas no tratamento-testemunha foram sempre inferiores àquelas dos tratamentos com fornecimento de fósforo (Tabelas 3 e 4). A fonte FR proporcionou menor produção no primeiro cultivo, embora não tenha diferido significativamente de outras, como FA e TM. O melhor resultado foi obtido com o uso de ST. Na segunda safra, houve uma melhoria de desempenho do FR, que não diferiu das demais fontes e apresentou tendência de superar o FA. Em valores absolutos, a melhor resposta foi observada para o TM (Tabela 3). Já no terceiro cultivo, no desdobramento da interação entre as fontes e os modos de aplicação, a única diferença estatística detectada entre tratamentos foi a maior produtividade do FR aplicado no sulco, comparativamente à aplicação a lanço (Tabela 4). Esses resultados corroboram observações de outros autores (HOROWITZ \& MEURER, 2003; KAMINSKI \& PERUZZO, 1997; RAJAN et al., 1996; SOUSA \& LOBATO, 2003) a respeito da eficiência de fosfatos reativos, a qual normalmente aumenta com o tempo, podendo até mesmo superar a eficiência de fontes solúveis nas safras seguintes ao primeiro cultivo.

Ao avaliar as produções de grãos nas três colheitas (Tabelas 3 e 4), verifica-se que, em valores absolutos, a aplicação do superfosfato triplo apresentou melhor resposta nas duas primeiras safras, sendo menos efetiva no terceiro cultivo. Inversamente, o desempenho dos fosfatos naturais, notadamente do FR, melhorou seguidamente ao longo dos cultivos. Comparativamente às demais, o termofosfato foi a fonte para a qual os ganhos de produtividade mantiveram-se mais estáveis ao longo do tempo.

TABELA 3 - Produção de grãos $\left(\mathrm{kg} \mathrm{ha}^{-1}\right)$ em função de fontes de fósforo na cultura do milho $\left(1^{\circ}\right.$ e $2^{\circ}$ cultivos, safras 2000/2001 e 2001/2002).

\begin{tabular}{ccc}
\hline Fontes de P & \multicolumn{3}{c}{ Safras } \\
\cline { 2 - 3 } & $\mathbf{2 0 0 0 / 2 0 0 1}$ & $\mathbf{2 0 0 1 / 2 0 0 2}$ \\
\hline ST & $4.297 \mathrm{a}$ & $7.971 \mathrm{a}$ \\
TM & $4.101 \mathrm{ab}$ & $8.129 \mathrm{a}$ \\
FR & $3.460 \mathrm{~b}$ & $7.509 \mathrm{ab}$ \\
FA & $3.959 \mathrm{ab}$ & $7.123 \mathrm{~b}$ \\
\hline Testemunha & $3.316^{*}$ & $5.269 * *$ \\
\hline
\end{tabular}

Médias seguidas de mesmas letras, nas colunas, não diferem estatisticamente pelo teste de Tukey, a 5\% de probabilidade. $* \mathrm{e}^{* *}=$ média do tratamento-testemunha difere $(<)$ em relação à média do fatorial pelo Teste $\mathrm{F}$, respectivamente, a $5 \%$ e $1 \%$ de probabilidade.

Ciênc. agrotec., Lavras, v. 30, n. 3, p. 458-466, maio/jun., 2006 
TABELA 4 - Produção de grãos $\left(\mathrm{kg} \mathrm{ha}^{-1}\right)$ em função de fontes e modos de aplicação de fósforo na cultura do milho (3ํㅜ cultivo, safra 2002/2003).

\begin{tabular}{|c|c|c|}
\hline \multirow[t]{2}{*}{ Fontes de $P$} & \multicolumn{2}{|c|}{ Modos de aplicacão } \\
\hline & Lanço & Sulco \\
\hline ST & 5.834 a $A$ & 6.042 a A \\
\hline $\mathrm{TM}$ & 6.111 a A & 6.667 a A \\
\hline FR & 5.301 a $\quad$ B & 7.160 a A \\
\hline FA & 5.926 a A & 6.019 a A \\
\hline
\end{tabular}

Médias seguidas de mesmas letras minúsculas, nas colunas, ou maiúsculas nas linhas não diferem estatisticamente pelo teste de Tukey, a $5 \%$ de probabilidade.

** = média do tratamento-testemunha difere $(<)$ em relação à média do fatorial (Teste $\mathrm{F}, p<0,01)$.

Devido à solubilidade distinta dos quatro fosfatos (Tabela 1), a dinâmica que se estabelece nas interações do P com o solo condiciona variações no suprimento à cultura $\mathrm{e}$ nas reações de indisponibilização do nutriente. Disso resultam diferenças na aquisição de $\mathrm{P}$ ao longo do ciclo, com consequiências sobre a produtividade do milho. Os efeitos conjuntos refletem nas taxas de exportação na colheita e no fósforo residual no solo, afetando as produções obtidas com as diferentes fontes nos cultivos subseqüientes.

Nesse contexto, as fontes ST e FR constituem exemplos contrastantes. Tratando-se de uma fonte de alta solubilidade, o superfosfato triplo libera prontamente grande parte do fósforo aplicado, incrementando de forma significativa a fração de P disponível no solo (PROCHNOW et al., 2003). A aquisição pelas raízes é favorecida, da mesma forma que as reações de fixação do nutriente, especialmente nos solos mais oxídicos (NOVAIS \& SMYTH, 1999). A exportação pode ser maior do que o normal (consumo de luxo) e o $\mathrm{P}$ do fertilizante pode passar rapidamente para formas pouco lábeis, com prejuízo da disponibilidade do nutriente para as safras seguintes. Em suma, nos primeiros anos após a aplicação, o ST favoreceria maior produtividade do milho, maior exportação e maior fixação do $\mathrm{P}$ fornecido. O raciocínio oposto se aplica ao FR. Em virtude da baixa solubilidade, o fosfato reativo libera gradualmente o $\mathrm{P}, \mathrm{o}$ que pode implicar em menor produção inicial, mas propicia maior efeito de longo prazo, beneficiando os cultivos posteriores (RAJAN et al., 1996). O fósforo não solubilizado de forma imediata permaneceria mais protegido das reações com o solo, minimizando o processo de fixação.

Quanto ao termofosfato, a solubilidade intermediária entre o superfosfato triplo e os fosfatos naturais parece ter sido determinante das boas produtividades observadas nas três safras (Tabelas 3 e 4). A liberação de parte do fósforo já no primeiro cultivo, suficiente para atender à demanda do milho, associada ao considerável efeito residual dessa fonte, pode garantir a estabilidade de produção ao longo do tempo. Ademais, os efeitos do termofosfato na elevação do $\mathrm{pH}$ e no suprimento de magnésio e silício (Tabela 1) podem ter conferido benefícios adicionais à cultura (GOEDERT et al., 1986; MALAVOLTA, 2003).

A despeito das marcantes diferenças em termos de reatividade e taxa de liberação de fósforo, características das quatro fontes em estudo (Tabela 1), chama atenção a similaridade das respostas obtidas para as combinações dos fatores testados no presente trabalho. Destacam-se os consideráveis níveis de produtividade alcançados no tratamento-testemunha (Tabelas 3 e 4). Isso difere do que seria típico em áreas de cerrado recém-abertas, nas quais, sem o fornecimento de fósforo, as produções alcançadas são muito baixas (SOUSA \& LOBATO, 2003). Similaridade de respostas a fontes e modos de aplicação de P tem sido reportada para solos em que a disponibilidade inicial do nutriente já era considerada satisfatória (ANGHINONI, 2003; KAMINSKI \& PERUZZO, 1997).

Os resultados aqui apresentados levam a deduzir que, a partir de certo nível de fertilidade do solo, a influência da fonte de fósforo e da forma de aplicação perde relevância e isso se dá de forma cada vez mais nítida no decorrer dos cultivos. Aparentemente, um importante aspecto relacionado a esse nivelamento dos efeitos dos tratamentos diz respeito ao tamponamento do solo, associado ao fato de que a área já havia sido adubada em épocas passadas. Em outras palavras, apesar das análises de solo serem indicativas de baixa disponibilidade de fósforo (Tabela 2; tratamento-testemunha), as reservas do solo, influenciadas pelo residual das antigas adubações, teriam proporcionado condições mínimas de suficiência, de modo a reduzir as discrepâncias de produtividade que deveriam resultar dos tratamentos aplicados. 
Um outro aspecto que merece destaque diz respeito ao detalhe da instalação do presente experimento em área já adubada e que não era utilizada para lavouras há alguns anos, estando coberta principalmente por capim-braquiarão, gramínea tida como bastante eficiente na absorção de fósforo, inclusive no aproveitamento de fontes pouco solúveis (GOEDERT et al., 1986; SOUSA et al., 2002). A braquiária também foi a vegetação espontânea predominante nos períodos de pousio durante condução do experimento. Esses fatos, associados ao mínimo revolvimento de solo após o primeiro cultivo, podem ter proporcionado uma condição peculiar em que o fósforo convertido para formas orgânicas seria biodisponível e representaria uma fonte importante do nutriente para o milho (SOUSA et al., 2002). Condição essa para a qual os extratores Mehlich 1 (dados não apresentados) e resina não seriam sensíveis. Pode-se supor, portanto, que as características do experimento foram similares ao que seria típico em áreas sob cultivo mínimo e, dessa forma, o P liberado dos fertilizantes seguiria uma dinâmica diferente do que normalmente ocorreria no sistema com preparo periódico do solo (SÁ, 2003; TOKURA et al., 2002). Em solos podzólicos e latossolos sob vegetação de gramíneas forrageiras, Guerra et al. (1996) observaram que o teor de carbono total estava altamente correlacionado com a fração lábil do fósforo orgânico e esta, por sua vez, com o teor de $\mathrm{P}$ disponível, reforçando a idéia de que a biodisponibilidade do nutriente não deve ser estritamente ligada às frações inorgânicas.

É preciso considerar, ainda, a influência climática nas respostas observadas. No primeiro cultivo, quando teoricamente esperariam-se efeitos mais contrastantes dos tratamentos, uma deficiência hídrica severa durante o ciclo do milho (Figura 1) pode ter nivelado, por baixo (Tabela 3), a produção entre tratamentos que implicariam em diferentes condições de disponibilidade de fósforo às plantas. A falta de água deve ter prejudicado as respostas principalmente às fontes de maior solubilidade (ST e TM). Situação inversa pode ter prevalecido no segundo cultivo, quando a oferta e a regularidade de chuvas foram altamente favoráveis à cultura, mesmo no tratamento sem fornecimento de fósforo (Tabela 3). A umidade do solo é um fator preponderante para que ocorra a solubilização e posterior difusão do fósforo no solo (ANGHINONI, 2003; MALAVOLTA et al., 1997; RAJAN et al., 1996), processos decisivos para que haja resposta das plantas à aplicação de adubos fosfatados.

\section{CONCLUSÕES}

As condições climáticas influenciaram os efeitos dos tratamentos, restringindo as respostas à adubação fosfatada no primeiro cultivo.

Nas duas primeiras safras, as fontes de maior solubilidade (superfosfato triplo e termofosfato) ocasionaram maiores produções. Os fosfatos naturais (fosfato de Araxá e fosfato reativo de Arad) apresentaram melhor desempenho com o tempo, equiparando-se às fontes mais solúveis no terceiro cultivo.

O uso do termofosfato associou bons rendimentos de grãos e estabilidade de produção ao longo do período avaliado. Contrariamente ao superfosfato triplo, o fosfato reativo foi a fonte de pior desempenho no ano da aplicação dos tratamentos, porém, apresentando pronunciado efeito residual, propiciou altas produções na terceira safra. A aplicação localizada do fosfato reativo resultou em maior produtividade no terceiro cultivo.

Apesar da baixa disponibilidade de P na análise do solo, o tratamento-testemunha apresentou considerável produção de grãos. O fato de a área já ter sido adubada e vegetada pelo capim-braquiarão em épocas passadas sugere a participação de formas orgânicas no suprimento de fósforo para o milho, contribuindo para reduzir as diferenças de respostas aos tratamentos.

\section{REFERÊNCIAS BIBLIOGRÁFICAS}

ALVAREZ, V. H.; NOVAIS, R. F.; BARROS, N. F.; CANTARUTTI, R. B.; LOPES, A. S. Interpretação dos resultados das análises de solos. In: COMISSÃ̃O DE FERTILIDADE DO SOLO DO ESTADO DE MINAS GERAIS. Recomendações para o uso de corretivos e fertilizantes em Minas Gerais: $5^{a}$ aproximação. Viçosa, 1999. p. 25-32.

ALVES, V. M. C.; VASCONCELLOS, C. A.; FREIRE, F. M.; PITTA, G. V. E.; FRANÇA, G. E.; RODRIGUES FILHO, A.; ARAÚJO, J. M.; VIEIRA, J. R.; LOUREIRO, J. E. Milho. In: COMISSÃO DE FERTILIDADE DO SOLO DO ESTADO DE MINAS GERAIS. Recomendações para o uso de corretivos e fertilizantes em Minas Gerais: $5^{\text {a }}$ aproximação. Viçosa, 1999. p. 314-316.

ANGHINONI, I. Fatores que interferem na eficiência da adubação fosfatada. In: SIMPÓSIO SOBRE FÓSFORO NA AGRICULTURA BRASILEIRA, 2003, Piracicaba. Anais... Piracicaba: Potafos/Anda, 2003. CD-ROM.

Ciênc. agrotec., Lavras, v. 30, n. 3, p. 458-466, maio/jun., 2006 
COELHO, A. M.; ALVES, V. M. C. Adubação fosfatada na cultura do milho. In: SIMPÓSIO SOBRE FÓSFORO NA AGRICULTURA BRASILEIRA, 2003, Piracicaba. Anais... Piracicaba: Potafos/Anda, 2003. CD-ROM.

EMPRESA BRASILEIRA DE PESQUISA AGROPECUÁRIA. Embrapa Solos. Embrapa Informática Agropecuária. Manual de análises químicas de solos, plantas e fertilizantes. Brasília, DF: Embrapa Comunicação para Transferência de Tecnologia, 1999. $370 \mathrm{p}$.

GOEDERT, W. J.; SOUSA, D. M. G.; LOBATO, E. Fósforo. In: GOEDERT, W. J. (Ed.). Solos dos cerrados: tecnologias e estratégias de manejo. São Paulo: Nobel, 1986. p. 129166.

GUERRA, J. G. M.; ALMEIDA, D. L.; SANTOS, G. A.; FERNANDES, M. S. Conteúdo de fósforo orgânico em amostras de solos. Pesquisa Agropecuária Brasileira, Brasília, v. 31, n. 4, p. 291299, abr. 1996.

HOROWITZ, N.; MEURER, E. J. Eficiência agronômica de fosfatos naturais. In: SIMPÓSIO SOBRE FÓSFORO NA AGRICULTURA BRASILEIRA, 2003, Piracicaba. Anais... Piracicaba: Potafos/Anda, 2003. CD-ROM.

KAMINSKI, J.; PERUZZO, G. Eficácia de fosfatos naturais reativos em sistemas de cultivo. Santa Maria: Núcleo Regional Sul da Sociedade Brasileira de Ciência do Solo, 1997. 31 p. (Boletim técnico, 3).

LOPES, A. S. Fosfatos naturais. In: COMISSÃO DE FERTILIDADE DO SOLO DO ESTADO DE MINAS GERAIS. Recomendações para o uso de corretivos e fertilizantes em Minas Gerais: $5^{a}$ aproximação. Viçosa, 1999. p. 65-66.

MALAVOLTA, E. Fósforo na planta e interação com outros elementos. In: SIMPÓSIO SOBRE FÓSFORO NA AGRICULTURA BRASILEIRA, 2003, Piracicaba. Anais... Piracicaba: Potafos/Anda, 2003. CD-ROM.

MALAVOLTA, E.; VITTI, G. C.; OLIVEIRA, S. A. Avaliação do estado nutricional das plantas: princípios e aplicações. 2. ed. Piracicaba: Potafos, 1997. 319 p.
MARTINEZ, H. E. P.; CARVALHO, J. G.; SOUZA, R. B. Diagnose foliar. In: COMISSÃO DE FERTILIDADE DO SOLO DO ESTADO DE MINAS GERAIS. Recomendações para o uso de corretivos e fertilizantes em Minas Gerais: $5^{a}$ aproximação. Viçosa, 1999. p. 143-168.

NOVAIS, R. F. Utilização de fosfatos naturais de baixa reatividade. In: COMISSÃO DE FERTILIDADE DO SOLO DO ESTADO DE MINAS GERAIS. Recomendações para o uso de corretivos e fertilizantes em Minas Gerais: $5^{\text {a }}$ aproximação. Viçosa, 1999. p. 62-64.

NOVAIS, R. F.; SMYTH, T. J. Fósforo em solo e planta em condições tropicais. Viçosa: UFV, 1999. 399 p.

OLIVEIRA, S. A. Análise foliar. In: SOUSA, D. M. G.; LOBATO, E. (Eds.). Cerrado: correção do solo e adubação. Planaltina: Embrapa Cerrados, 2002. p. 245256.

PROCHNOW, L. I.; ALCARDE, J. C.; CHIEN, S. H. Eficiência agronômica dos fosfatos totalmente acidulados. In: SIMPÓSIO SOBRE FÓSFORO NA AGRICULTURA BRASILEIRA, 2003, Piracicaba. Anais... Piracicaba: Potafos/Anda, 2003. CD-ROM.

RAIJ, B. van; QUAGGIO, J. A. Métodos de análise de solos para fins de fertilidade. Campinas: Instituto Agronômico, 1983. 31 p. (Boletim, 81).

RAIJ, B. van; QUAGGIO, J. A.; CANTARELLA, H.; ABREU, C. A. Interpretação de resultados de análise de solo. In: RAIJ, B. van; CANTARELLA, H.; QUAGGIO, J. A.; FURLANI, A. M. C. (Eds.). Recomendações de adubação e calagem para o Estado de São Paulo. Campinas: Instituto Agronômico, 1996. p. 8-13.

RAJAN, S. S. S.; WATKINSON, J. H.; SINCLAIR, A. G. Phosphate rocks for direct application to soils. Advances in Agronomy, New York, v. 57, p. 77-159, 1996.

RESENDE, A. V. Fontes e modos de aplicação de fósforo para o milho em solo cultivado da região do Cerrado. 2004. 169 p. Tese (Doutorado em Solos e Nutrição de Plantas) - Universidade Federal de Lavras, Lavras, 2004. 
SÁ, J. C. M. Adubação fosfatada no sistema de plantio direto. In: SIMPÓSIO SOBRE FÓSFORO NA AGRICULTURA BRASILEIRA, 2003, Piracicaba. Anais... Piracicaba: Potafos/Anda, 2003. CD-ROM.

SOUSA, D. M. G.; LOBATO, E. Adubação fosfatada em solos da região do Cerrado. Informações Agronômicas, Piracicaba, n. 102, p. 1-16, jun. 2003. Encarte técnico.

SOUSA, D. M. G.; LOBATO, E.; REIN, T. A. Adubação com fósforo. In: SOUSA, D. M. G.; LOBATO, E. (Eds.). Cerrado: correção do solo e adubação. Planaltina: Embrapa Cerrados, 2002. p. 147-168.

TOKURA, A. M.; FURTINI NETO, A. E.; CURI, N.; FAQUIN, V.; KURIHARA, C. H.; ALOVISI, A. A. Formas de fósforo em solo sob plantio direto em razão da profundidade e do tempo de cultivo. Pesquisa Agropecuária Brasileira, Brasília, v. 37, n. 10, p. 1467 1476, out. 2002.

Ciênc. agrotec., Lavras, v. 30, n. 3, p. 458-466, maio/jun., 2006 